\title{
Satisfação com a Formação Superior e Transição para o Trabalho
}

\section{Satisfaction with Higher Education and Transition to Work}

\author{
Elisabete Sousa \& Carlos Gonçalves \\ Universidade do Porto, Porto, Portugal
}

\begin{abstract}
Resumo: A atual crise económica das sociedades ocidentais contemporâneas, com o aumento exponencial do desemprego, vai adiando a entrada no mundo do trabalho das gerações mais jovens que procuram o primeiro emprego, antecipando este clima de insegurança para os estudantes que se encontram numa fase de conclusão da sua formação superior. Esta investigação teve como objetivo analisar as perceções que os estudantes finalistas de uma instituição de ensino superior, da área da economia e da gestão, atribuem à transição da conclusão da sua formação para o mercado de trabalho na sua relação com a satisfação com a formação realizada, tendo em conta as variáveis género, ciclo de estudo, associativismo, e estatuto de residência. Os instrumentos utilizados neste estudo, numa amostra de 227 estudantes, foram: um questionário sociodemográfico construído no âmbito deste estudo; a Escala de Significados da Transição do Ensino Superior para o Trabalho (Monteiro, Santos, \& Gonçalves, 2015) e a Escala de Satisfação com a Formação Superior (Ramos $\&$ Gonçalves, 2014). Os resultados apontam para diferenças significativas nas variáveis género, ciclo de estudos, e associativismo, no que respeita à perceção da transição da universidade para o trabalho, e no que respeita à satisfação sentida com a formação.
\end{abstract}

Palavras-chave: transição, satisfação, mercado de trabalho, ensino superior.
Abstract: The current economic crisis of contemporary western societies, along with the exponential increase of unemployment, will delay the entry into the working world of younger generations looking for their first job, anticipating this climate of uncertainty for students who are in the final phase of their higher education. This research aimed to analyze the perceptions that the graduate students of a higher education institution, in the economics and management area, ascribe to the transition into the labor market, after concluding their studies, regarding the degree of satisfaction with the academic training received, taking into account the variables of gender, study life-cycle, associativity, and residence status. The instruments used in this study, based on a sample of 227 students, were: a socio-demographic questionnaire, created within the framework of this study; a scale of the meanings of transition from higher education to work (Escala de Significados da Transição do Ensino Superior para o Trabalho; Monteiro, Santos, \& Gonçalves, 2015), and a higher education satisfaction scale (Escala de Satisfação com a Formação Superior; Ramos \& Gonçalves, 2014). The results indicate significant differences regarding gender, study lifecycle and associativity with regard to the perception of the transition from university to work, and the degree of satisfaction felt towards the academic training received.

Keywords: transition, satisfaction, job market, higher education.

Contato: C. Gonçalves. Rua Alfredo Allen 535, 4200-135 Porto, Portugal. Correio eletrônico: carlosg@ fpce.up.pt

Como citar: Sousa, E. \& Gonçalves, C. (2016). Satisfação com a formação superior e transição para o trabalho. Revista de Psicología, 25(1), 1-20.

http://dx.doi.org/10.5354/0719-0581.2016.41690 


\section{Introdução}

Nas sociedades ocidentais contemporâneas vivem-se tempos de profunda crise económica com impactos inquestionáveis no acesso ao mundo do trabalho, com o aumento exponencial do número dos desempregados, da precarização do trabalho, dos trabalhos temporários ou mesmo de desemprego estrutural (Gonçalves, 2014). Diante deste cenário histórico e social, o mercado de trabalho tornou-se cada vez mais competitivo, obrigando as novas gerações a confrontarem-se com situações marcadas pela incerteza e imprevisibilidade em relação à entrada no mundo do trabalho. Esta conjetura histórica e social com estas marcas, o crescente aumento dos diplomados do ensino superior (Urbano, 2011) associado ao facto de o mundo do trabalho ser cada vez mais seletivo no processo de recrutamento dos candidatos que possuem formação superior (Delors et al., 2010), produz maior competitividade entre os jovens universitários, que se veem obrigados a destacar-se e a competir com o seu grupo de pares, para garantirem sua entrada no mercado de trabalho.

A educação superior deixou de representar um status prestigiante de uma minoria extremamente reduzida da população, para se constituir num direito de cidadania para a aquisição certificada de conhecimentos e competências de alta qualificação por parte de um conjunto cada vez mais vasto de pessoas (Costa \& Lopes, 2008). O aumento desta procura está ainda relacionado com as expetativas de mobilidade social, ambicionada pelas novas gerações, que tencionam obter um trabalho mais satisfatório do que os seus ascendentes (Monteiro, 2015).

Tal aumento foi acompanhado pelo desenvolvimento de metodologias de ensino e aprendizagem cada vez mais modernizadas, assim como pelo aumento do número de universidades, e da competitividade entre as mesmas, devido à elevada procura (Butt \& Rehman, 2010; Kehm \& Stensaker, 2009). A competitividade é acentuada pela recente existência de rankings, que influenciam o prestígio e a forma como a universidade é vista por entidades e pessoas externas (Kehm \& Stensaker, 2009). Porém, estas recentes alterações não têm sido correspondidas ao nível do acesso ao mundo do trabalho por parte destes jovens cada vez mais qualificados. Este cenário poderia afastar os jovens das instituições de ensino superior ou tornar este tipo de formações menos apetecíveis.

Contudo, como já notou Alves (1998), a partir dos inquéritos realizados à população estudantil portuguesa em 1997, os estudantes portugueses apresentam, cada vez mais, aspirações de frequência e obtenção de um diploma de ensino superior. Estas aspirações decorrem de elevadas expetativas de mobilidade social, da crença na posse de um diploma do ensino superior como um escudo protetor perante o desemprego e a precariedade, ou como estratégia para neutralizar possíveis trajetórias de desclassificação social.

A globalização, que aporta mudanças económicas e culturais, também contribuiu para todas as mudanças ocorridas no contexto universitário (Marginson \& van der Wende, 2007). A educação constrói aprendizagem e desenvolvimento e, por isso, é um elemento chave para o desenvolvimento global das sociedades, para além de que proporciona aos seus membros oportunidades de pesquisa, comunicação e interações sociais e interculturais, fatores que fazem evoluir a globalização (Marginson \& van der Wende, 2007). Assim, apesar das dificuldades de acede- 
rem ao trabalho qualificado para o qual se formaram, os jovens portugueses continuam a procurar e a valorizar o investimento na sua formação superior. Leuze (2011) defende que, apesar das dificuldades em conseguir emprego após a conclusão do curso, os jovens mais qualificados têm menos dificuldade em arranjar emprego do que os jovens com um grau de escolaridade menor, o que sugere que, apesar da crise económica atual, um diploma universitário continua a ter bastante valor perante as entidades empregadoras.

A transição do ensino superior para o trabalho é conceptualizada como uma transição desenvolvimentista, que envolve necessidades de adaptação e reorganizações vivenciais (Campos, 1993; Schlossberg, 1981). Por isso, como qualquer outra transição, é caraterizada por marcas de imprevisibilidade e stress porque implica abandonar uma zona de conforto/adaptação -a faculdade- para algo de novo, o mundo do trabalho turbulento, implicando reorganizações pessoais e sociais (Chickering \& Schlossberg, 1995). A capacidade de lidar com essas transições depende da organização de cada pessoa e do significado que elas atribuem às mudanças produzidas pela nova fase da sua vida, sendo relevante enfrentar os desafios com expetativas realistas (Chickering \& Schlossberg, 1995; Young et al., 2011).

A transição da universidade para o trabalho tem impacto na vida dos jovens, na medida em que altera a vida, os papéis, as relações e as rotinas (Schlossberg, 2011). Esta conceptualização, enquanto transição desenvolvimentista, é extremamente relevante na medida em que, como nos diz Campos (1993), se focaliza a atenção não apenas no maior ou menor stress que o acontecimento em si provoca, mas também nas exigências de mudança que im- põem, elas próprias, também fontes de stress, tanto mais que o processo de transição poderá ser positivo ou negativo em termos desenvolvimentistas.

A literatura vem sublinhando uma relação estreita entre a experiência de sucesso e satisfação com a formação e a transição do sujeito no mercado de trabalho (Monteiro, 2015; Ramos \& Gonçalves, 2014). Pascarella e Terenzini (2005) defendem que o bom desempenho académico dos estudantes durante a formação superior tem um impacto positivo nas primeiras experiências da transição para o mercado de trabalho. Ou seja, se o indivíduo assimilar e consolidar os conhecimentos adquiridos ao longo da sua formação, esses conhecimentos refletir-se-ão, posteriormente, no contexto profissional, tornando-o mais confiante e mais bem-sucedido.

Segundo Magalhães e Silva (2010) o trabalho é uma fonte de realização pessoal, que satisfaz as necessidades do ser humano, ao mesmo tempo que cria novos desafios. A transição para o mercado de trabalho e o consequente sucesso do indivíduo no mesmo estão ainda relacionados com algumas capacidades e competências que os alunos foram desenvolvendo ao longo da sua formação, como a capacidade de resolver problemas, de análise crítica, capacidade de inovação, de adaptação e cooperação que influenciam a forma como o indivíduo se adapta à sua nova realidade do mundo do trabalho (Lima \& Coimbra, 2004).

A satisfação que os estudantes manifestam com a formação superior é um dos fatores que poderá influenciar a transição da universidade para o trabalho. Essa satisfação depende de inúmeras dimensões por parte do sujeito e das instituições do ensino superior. As expetativas realistas e ajustadas, acerca da formação e o contexto onde 
ocorre, poderão contribuir para a satisfação como o percurso formativo. Se, pelo contrário, o estudante apresentar baixas expetativas acerca dos serviços prestados pela faculdade, do desempenho dos professores, do ambiente/clima físico e relacional da instituição, o sujeito sentir-se-á, provavelmente, desiludido e insatisfeito.

Essa situação poderá levar os estudantes a sentirem-se desmotivados e, em situações extremas, a abandonarem o curso/instituição (Ramos \& Gonçalves, 2014). $\mathrm{O}$ facto de as expetativas serem correspondidas ou não, influencia a adaptação, satisfação, motivação, e desempenho académica (Almeida \& Vasconcelos, 2008).

Walter, Tontini e Domingues (2005) suportam a ideia de que o sucesso das universidades está relacionado com o facto de os alunos estarem satisfeitos com a sua experiência académica, sendo mesmo um preditor da eficácia do ensino. Segundo Alves, Alves e Chaves (2012), os licenciados tendem, de forma geral, a demonstrarem-se "bastante satisfeitos com o seu percurso e formação académica" (p. 114), sendo residuais os que revelaram que mudariam a sua trajetória de formação, caso tivessem oportunidade. Neste mesmo estudo, é revelado que o percurso académico tem grande influência no desenvolvimento pessoal dos indivíduos.

Ainda, segundo Chickering e Gamson (1987), a universidade deve reger-se por alguns princípios no que concerne à influência que exerce sobre os estudantes, tendo impactos sobre a satisfação. Estes princípios são: encorajar o contacto entre os estudantes e a instituição; desenvolver as relações interpessoais e cooperação entre os estudantes; utilizar técnicas de aprendizagem ativa; receber feedback; dedicar tempo às suas tarefas; ter as expetativas elevadas; e, respeitar as diferentes capacidades e formas de aprendizagem. Todos esses princípios têm maioritariamente como objetivos motivar os estudantes, fazê-los refletir acerca dos seus planos futuros e capacidades, para que possam desenvolver-se e evoluir (Chickering \& Gamson, 1987).

Outro fator que poderá ter um peso relevante na integração e satisfação académica é o associativismo. Neste estudo, o associativismo refere-se à multiplicidade de atividades extracurriculares, que podem ser, por exemplo, atividades de voluntariado, criação de grupos que apoiem ideias empreendedoras e atividades de lazer, tais como grupos corais, grupos desportivos e de atividades culturais na comunidade.

Pascarella e Terenzini (2005) comprovaram que o envolvimento em atividades extracurriculares, principalmente na participação nos organismos de gestão das instituições que frequentam, como por exemplo, a associação de estudantes, o conselho pedagógico e o conselho geral da faculdade, tem um impacto significativo no desenvolvimento de competências interpessoais, de liderança e de gestão, na futura vida profissional. Fazer parte destes grupos e participar ativamente nestas funções permite aos indivíduos terem consciência de como funciona um grupo/entidade, o que faz com que estejam melhor preparados e adequem as suas expetativas ao seu futuro contexto profissional. A participação em grupos extracurriculares poderá proporcionar a criação de novas redes amizades e relações contribuindo para a adaptação social e académica dos alunos (Aspinwall \& Taylor, 1992).

Partindo da revisão do estado arte, o presente estudo pretende avaliar a forma como os estudantes finalistas de uma instituição de ensino superior do grande Porto, 
na área de economia e gestão, percecionam a transição do ensino superior para o mercado de trabalho, tendo em conta a perceção da satisfação com a formação superior realizada. Pretende-se compreender de que forma estas duas dimensões, a satisfação com a formação realizada e a transição da formação para o trabalho, se correlacionam, bem como relacioná-las com outras variáveis, como o género, ciclo de estudos e associativismo.

Como a investigação neste domínio é escassa, ou mesmo omissa, intencionalmente não se formularam hipóteses de investigação, por falta de literatura consistente para as sustentar, mas optou-se pelas seguintes questões de investigação: a) será que a satisfação com a formação realizada se relacionará com a transição da formação para o trabalho?; b) haverá diferenças significativas destas dimensões com as variáveis sociodemográficas, como o género, o ciclo de estudos e o associativismo?

\section{Método}

\section{Participantes}

A amostra deste estudo é constituída por 227 estudantes do $3^{\circ}$ ano das licenciaturas em Economia e Gestão e do $1^{\circ}$ e $2^{\circ}$ anos de vários mestrados, das mesmas áreas, numa instituição de ensino superior do Grande Porto. Saliente-se que esta instituição, onde foi desenvolvido o estudo, é das mais cotadas em termos do ranking nacional, tendo a classificação mais elevada de acesso ao ensino superior nos últimos anos, nas áreas de economia e gestão.

As idades dos participantes variam entre os 20 e os 56 anos $(M=23.11 ; D P=$ 4.06), entre os quais $39.2 \%$ são do género masculino, e $60.8 \%$ pertencem ao género feminino; $47.6 \%$ são estudantes do $3^{\circ}$ ano de licenciatura, enquanto $52.4 \%$ são alunos de $1^{\circ}$ e $2^{\circ}$ ano de mestrado. Quanto à variável do associativismo, $40.5 \%$ dos inquiridos revelaram que já pertenceram a algum organismo de estudantes na faculdade e $59.5 \%$ que referem não terem realizado qualquer experiência de associativismo.

\section{Instrumentos}

Neste estudo foram utilizados dois instrumentos, construídos no âmbito da investigação desenvolvida nos últimos anos no contexto português sobre este domínio do saber: a Escala de Significados da Transição do Ensino Superior para o Trabalho (ESTEST; Monteiro et al., 2015) e a Escala de Satisfação com a Formação Superior (ESFS; Ramos \& Gonçalves, 2014). A opção por esses instrumentos justifica-se porque avaliam as dimensões que se pretendem no âmbito deste estudo e porque foram construídos no contexto sociocultural português nos últimos anos, revelando elevadas qualidades psicométricas.

Utilizou-se ainda um questionário sociodemográfico construído, no âmbito deste estudo, focalizando-se em seis questões chave, à volta dos objetivos da investigação e recolha de alguns dados sociodemográficos como, o género, ciclo de estudos e experiência de associativismo.

Considera-se, neste estudo, que o associativismo se operacionaliza na participação em atividades extracurriculares organizadas pelos vários organismos de estudantes (Ramos, 2008). Maioritariamente, estes grupos visam o desenvolvimento de competências pessoais e sociais. Enumeram-se alguns exemplos de associativismo: pertencer à associação de estudantes da faculdade; participação em órgãos de gestão (como o conselho pedagógico, assembleia 
geral da faculdade); integrar as tunas ${ }^{1}$; os grupos de caráter solidário e de voluntariado social; os grupos de mentoria: estudantes mais velhos que acolhem e colaboram na integração dos estudantes do $1^{\circ}$ ano no ambiente institucional, etecetera.

A ESTEST avalia as perceções antecipadas da transição da formação para o mercado do trabalho, sendo constituída por 20 itens, com resposta tipo Likert de seis opções, com quatro fatores: 1) A Realização Pessoal: refere-se à avaliação da satisfação com o trabalho, como uma oportunidade de colocar em prática os conhecimentos obtidos no curso superior (exemplo de item: "Será um motivo de orgulho entrar no mercado de trabalho depois de terminar o curso"); 2) A Incerteza: representa o medo e a ansiedade provocados pela dificuldade em prever o que acontecerá após a conclusão da formação/curso (exemplo de item: "Sinto medo quando penso na transição para o mercado de trabalho"); 3) O Desemprego: centra-se nas dificuldades inerentes à procura de emprego (exemplo de item: "O fim do meu curso levar-me-á a passar por uma situação de desemprego"); 4) A Responsabilidade: relaciona-se com as tarefas relacionadas com o trabalho serem de uma responsabilidade acrescida (exemplo de item: "Trabalhar significa que determinadas tarefas estarão dependentes de mim") (Monteiro et al., 2015).

A ESTEST apresenta valores elevados de consistência interna nas quatro subescalas, compreendidos entre .79 e .90 , e uma variância explicada de $64.7 \%$, ou seja, as quatro subescalas contribuem $64.7 \%$ para a explicação da dimensão global transição do ensino superior para o trabalho.

\footnotetext{
${ }^{1}$ Grupo musical de natureza estudantil e académica.
}

A ESFS (Ramos \& Gonçalves, 2014) avalia as perceções dos estudantes quanto à satisfação com a formação realizada. A ESFS é constituída por 25 itens, com um Likert de seis possibilidades de resposta, organizando-se em quatro fatores; 1) $\mathrm{O}$ Institucional: centra-se na análise das perceções e significados relacionados com a qualidade dos serviços universitários prestados aos estudantes (exemplo de item: "espaço e condições físicas para a aprendizagem"); 2) O Sócio Relacional: foca-se na avaliação das perceções e significados intrínsecos ao processo de integração e de estabelecimento de relações dos estudantes com toda a comunidade académica (exemplo de item: "qualidade do relacionamento entre os estudantes"); 3) As Expetativas de Integração Profissional: relaciona-se com a análise das perceções e significados atribuídos ao processo de transição do ensino superior para o mercado de trabalho (exemplo de item: "articulação da faculdade com o mercado de trabalho no sentido da integração profissional dos estudantes"); e 4) Os Recursos Pessoais do Estudante: tem a ver com a autoavaliação que os estudantes fazem das suas próprias competências para lidar com as exigências do ensino superior (exemplo de item: "capacidade que possui para lidar com os níveis de exigência dos trabalhos propostos").

A ESFS revela também excelentes qualidades psicométricas com alfas de Cronbach de consistência interna que oscilam entre .81 a .87 e com um valor de variância explicada total de $61.9 \%$; ou seja, as quatro subescalas contribuem $61.9 \%$ para a explicação da dimensão global, satisfação com a formação superior.

\section{Procedimentos}

A recolha de dados foi feita a partir de uma plataforma online, Google Docs, onde fo- 
ram colocados os questionários, que estiveram disponíveis para preenchimento durante os meses março e abril de 2015. O pedido para a colaboração voluntária no estudo foi feito através de email pessoal, cedido pela associação de estudantes e serviços académicos da faculdade e com o consentimento diretor da faculdade.

Esta forma de recolha de dados online tem algumas vantagens, como o facto de ser possível chegar a um maior número de sujeitos, pois não existem constrangimentos como o agendamento de datas e locais para a administração presencial, fazendo com que não haja prejuízo para os professores em termos de tempo (Ramos, 2008); permitir aos respondentes manter o seu anonimato sem se confrontar no face a face com o investigador, o que poderá fazer com que as respostas sejam mais sinceras (Hoerger \& Currell, 2012; Santos, 2009); o participante pode decidir qual o tempo mais adequado para responder, podendo, inclusive, interromper e retomar a resposta ao mesmo; não existem praticamente custos monetários, contrariamente à recolha feita face a face, o que poderá fazer com que seja possível abranger uma maior amostra (Hoerger \& Currell, 2012; Pinheiro \& da Silva, 2004); sem dúvida, é um processo mais rápido e menos burocrático na recolha de dados.

Contudo, a recolha de dados online apresenta os seus inconvenientes, não é possível controlar se o mesmo estudante respondeu ao questionário mais do que uma vez, se as caraterísticas do mesmo correspondem ao pretendido pelo estudo, se deixou questões por responder, facto que se poderia verificar se o inquérito fosse face a face (Marconi \& Lakatos, 1985; Monteiro, 2015). Como Pinheiro e da Silva (2004) defendem um contacto mais pessoal e intimista com o inquirido poderia fazer com que houvessem mais respostas, aspeto esse que não foi considerado neste estudo.

Após a recolha dos dados, a análise foi realizada através do programa informático IBM SPSS (versão 20).

\section{Resultados}

Na tabela 1 são apresentados os resultados referentes à transição em função do género, em que foi utilizada uma Análise de Variância (ANOVA) entre grupos, uma vez que compara diferentes grupos relativamente às mesmas questões. Verificou-se que existem diferenças significativas entre o género masculino e feminino no que respeita aos significados que atribuem à transição da formação para o mercado de trabalho, nas quatro dimensões presentes, registando-se que as mulheres têm valores superiores nas quatro dimensões.

Tabela 1

Diferenças nas subescalas da ESTEST por género

\begin{tabular}{lcc}
\hline \multirow{2}{*}{ Género } & $\begin{array}{c}\text { Masculino } \\
(n=89)\end{array}$ & $\begin{array}{c}\text { Feminino } \\
(n=138)\end{array}$ \\
\cline { 2 - 3 } & \multicolumn{2}{c}{$M(D P)$} \\
\hline Realização Prof. & $4.59(0.96)$ & $5.07(0.80)^{*}$ \\
Incerteza & $3.04(1.12)$ & $4.11(1.02)^{*}$ \\
Desemprego & $2.85(1.20)$ & $3.64(1.18)^{*}$ \\
Responsabilidade & $4.84(0.70)$ & $5.24(0.57)^{*}$ \\
\hline
\end{tabular}

Nota: $M=$ Média; $D P=$ Desvio Padrão. $* p<.05$

$\mathrm{Na}$ dimensão realização profissional, as mulheres acreditam que quando entrarem no mercado de trabalho, se sentirão realizadas e poderão colocar em prática aquilo que aprenderam no ensino superior, apresentando resultados superiores aos homens. Este resultado pode ser explicado pelo investimento e preparação que as mulheres fizeram nas suas carreiras, 
percecionando a entrada no mundo do trabalho como uma oportunidade de realização pessoal e de assumir responsabilidades pessoais e sociais para encontrarem o seu espaço num contexto onde ainda predomina o masculino, e tenham conquistado o seu lugar numa situação de desvantagem (Fernandes, 2014; Monteiro, 2015; Oliveira, 2011).

De forma geral, as mulheres sentem-se mais inseguras em relação aos homens, no que concerne ao processo de transição para o trabalho, apresentando resultados superiores na dimensão incerteza. Relativamente à dimensão desemprego, as mulheres apresentam novamente resultados superiores, acreditando que terão dificuldades na procura e obtenção de emprego.

Na última dimensão, responsabilidade, as mulheres apresentam novamente resultados superiores, em comparação com os homens. Embora a literatura seja exígua para sustentar estes resultados, poderão ser compreendidos pelo facto de, ainda nos dias de hoje, os homens terem mais facilidade em entrar no mundo do trabalho e com melhores remunerações, enquanto as mulheres ainda são vítimas de discriminação do sexo; por isso, as mulheres participantes deste estudo sentem-se mais inseguras quanto à possibilidade de entrarem no mundo do trabalho, e terem emprego, aquando a conclusão do curso.

Atualmente ainda existem muitas desigualdades de género no mercado de trabalho, especialmente no que respeita à progressão de carreira das mulheres, sendo que a maioria dos cargos de chefia e os salários mais elevados são atribuídos aos homens (Nogueira, 2006; Oliveira, 2011).

Na tabela 2, o teste estatístico utilizado foi, novamente, a ANOVA entre grupos, com $o$ intuito de apurar se existiriam diferenças significativas entre os alunos que fazem ou já fizeram parte de organismos de estudantes, no que toca à transição. Constatou-se que existem diferenças significativas entre estes dois grupos de estudantes, em três das dimensões em estudo.

Tabela 2

Diferenças nas subescalas da ESTEST por associativismo

\begin{tabular}{|c|c|c|}
\hline & $\begin{array}{l}\operatorname{Sim}(\mathrm{S}) \\
(n=92)\end{array}$ & $\begin{array}{l}\text { Não }(\mathrm{N}) \\
(n=135)\end{array}$ \\
\hline & \multicolumn{2}{|c|}{$M(D P)$} \\
\hline Realização Prof. & $4.75(0.94)$ & $4.97(0.85)$ \\
\hline Incerteza & $3.43(1.25)$ & $3.87(1.09)^{*}$ \\
\hline Desemprego & $2.92(1.25)$ & $3.61(1.09)^{*}$ \\
\hline Responsabilidade & $4.96(0.72)$ & $5.17(0.59)^{*}$ \\
\hline
\end{tabular}

Nota: $M=$ Média; $D P=$ Desvio Padrão $* p<.05$

Quanto às diferenças por associativismo, verifica-se que as diferenças são significativas em três dimensões: incerteza, desemprego e responsabilidade, registando-se valores superiores nos estudantes sem experiência de associativismo. Estes resultados eram esperados, uma vez que autores como Pascarella e Terenzini (2005) demonstram que a participação dos estudantes em atividades extracurriculares tem uma influência bastante significativa no desenvolvimento de competências sociais, e de liderança, o que poderá fazer a diferença na sua futura vida profissional. Com esta experiência prévia, é provável que os sujeitos se sintam melhor preparados para a transição, assim como para o desempenho de tarefas profissionais, uma vez que, provavelmente, desempenharam funções semelhantes nos grupos dos quais fizeram parte. Assim, é esperado que os alunos que fazem parte de organismos estudantis se sintam menos inseguros, e esperem maior facilidade na procura de emprego após a conclusão do curso, facto que se verificou através das dimensões incerteza e desemprego. 
$\mathrm{Na}$ dimensão responsabilidade, os alunos com associativismo sentem que a transição para o mercado de trabalho não lhes trará tanta responsabilidade como os alunos sem associativismo. Isto poderá ser explicado pelo facto dos estudantes com experiência de associativismo já terem desempenhado tarefas importantes, as quais lhes foram exigidas responsabilidades. Assim, provavelmente não sentirão uma grande diferença quando transitarem para o mundo do trabalho, contrariamente aos estudantes que não fazem, nem fizeram parte de qualquer grupo.

No sentido de apurar se existiriam diferenças entre os alunos que frequentam licenciatura, e aqueles que frequentam mestrado em relação ao nível de satisfação com a formação superior, utilizou-se igualmente a ANOVA entre grupos. A tabela 3 demonstra que existem diferenças significativas em duas das dimensões em estudo, entre estes dois grupos de sujeitos.

Tabela 3

Diferenças nas subescalas da ESFS por ciclo de estudos

\begin{tabular}{lll}
\hline & $\begin{array}{c}\text { Licenciatura } \\
(n=108)\end{array}$ & $\begin{array}{l}\text { Mestrado } \\
(n=119)\end{array}$ \\
\cline { 2 - 3 } & \multicolumn{2}{c}{$M(D P)$} \\
\hline Institucional & $3.63(0.76)$ & $3.83(0.76)^{*}$ \\
Sócio relacional & $4.08(0.98)$ & $4.10(0.75)$ \\
Expetativas & $4.33(0.67)$ & $4.21(0.74)$ \\
Recursos pessoais & $4.38(0.67)$ & $4.68(0.66)^{*}$ \\
\hline
\end{tabular}

Nota: $M=$ Média; $D P=$ Desvio Padrão $* p<.05$
Na variável independente ciclo de estudos verifica-se que existem diferenças significativas em duas das dimensões. Uma delas é a dimensão institucional, em que os alunos de mestrado obtiveram pontuações superiores. Através deste resultado podemos concluir que os alunos mais velhos atribuem maior significado aos serviços prestados pela faculdade.

A outra dimensão diz respeito aos recursos pessoais, em que os alunos de mestrado apresentam igualmente resultados superiores. Este resultado poderá ser explicado pelo facto de os alunos de mestrado serem, de forma geral, mais velhos e devido a isso terem maior consciência das capacidades e dificuldades que possuem para lidar com o nível de exigência do curso, e com o volume de trabalho proposto. Para além disso, é provável que os alunos mais velhos já tenham vivido mais experiências de sucesso e desenvolvimento ao longo do seu percurso universitário do que os alunos mais novos (Ramos, 2008), o que faz com que esta perceção acerca dos seus recursos seja mais elevada.

No sentido de compreender se as dimensões dos diferentes instrumentos utilizados neste estudo estavam correlacionadas, recorreu-se à análise de coeficientes de correlação de Pearson. A tabela 4 apresenta os resultados obtidos.

Tabela 4

Correlações entre as dimensões da ESTEST, as dimensões da ESFS

\begin{tabular}{llcccc}
\hline & & Realização Prof. & Incerteza & Desemprego & Responsabilidade \\
\hline Institucional & $r$ & $.250^{*}$ & .056 & .036 & $.235^{*}$ \\
Sócio relacional & $r$ & $.185^{*}$ & -.082 & -.117 & .108 \\
Expetativas & $r$ & $.311^{*}$ & -.014 & $-.334^{*}$ & $.191^{*}$ \\
Recursos pessoais & $r$ & $.173^{*}$ & $-.312^{*}$ & $-.235^{*}$ & .057 \\
\hline
\end{tabular}

Nota: $r=$ coeficientes de correlação de Pearson.

$* p<.05$ 
De acordo com a tabela 4 referente às correlações, o que emerge como mais relevante é que as quatro dimensões da satisfação com a formação superior (institucional, sócio relacional, expetativas, e recursos pessoais) se correlacionam positivamente com a variável da transição para o trabalho: realização profissional. Por outro lado, apenas as variáveis institucional e expetativas se relacionam com a responsabilidade.

Este resultado parece significar que a satisfação com a formação tem impactos importantes na realização pessoal e responsabilidade dos futuros profissionais que frequentam esta instituição de ensino superior. Ou seja, as oportunidades que a formação proporciona como o espaço físico da faculdade, os eventos de lazer e científicos organizados, a relação com colegas e professores, a integração na faculdade e a qualidade da formação, por exemplo, são percecionados positivamente como o contexto privilegiado em que o estudante adquire as competências para se realizar e assumir responsabilidades para o seu futuro profissional. Ainda, a realização que o indivíduo poderá sentir com a sua futura profissão poderá estar relacionada com a faculdade em que tirou o curso. Neste caso, se considerar que a sua faculdade tem um ensino de qualidade e prestígio, a probabilidade de se sentir profissionalmente realizado será superior (Ramos, 2008).

Ainda, as dimensões incerteza e recursos pessoais encontram-se negativamente relacionadas, o que significa que quanto mais positiva for a perceção das competências e capacidades que o indivíduo acredita que possui para lidar com a exigência do curso, menor é a sensação de incerteza relativamente à transição para o mundo do trabalho. Este resultado seria expectável, uma vez que o sujeito ao percecionar que o seu capital de competências pessoais e sociais se vai desenvolvendo ao longo da formação, mais confiante se sente para enfrentar os desafios e constrangimentos da conjuntura histórica e social da transição da formação para o trabalho como a incerteza, acreditando que poderá ser bem sucedido neste processo de transição. De acordo com de Melo e Borges (2007), os jovens que se consideram mais proativos têm menos sentimentos de angústia e incerteza face à procura de emprego, o que faz com que sejam mais empreendedores nos seus projetos.

\section{Discussão}

Apesar de o tema da transição associado à satisfação com a formação ter sido ainda pouco explorado na literatura, e o estado da arte ser demasiado exígua para permitir sustentar os resultados encontrados, podemos considerar que os resultados obtidos poderão ser um contributo para compreendermos esta temática de grande atualidade para a investigação e de grande relevância social.

Um dos principais resultados encontrados está relacionado com a diferença entre os géneros feminino e masculino relativamente à antecipação da transição, sendo que as mulheres se sentem mais inseguras e ansiosas. Estes resultados poderão justificar-se pelo facto de, na atualidade, apesar dos avanços registados nas sociedades ocidentais para uma maior igualdade entre os géneros, os homens ainda têm mais facilidade em entrar no mundo do trabalho, e com melhores remunerações, do que as mulheres, que ainda são discriminação na sua condição feminina (Fernandes, 2014). Por isso, as mulheres participantes deste estudo sentem-se mais inseguras quanto à possibilidade de entrarem no mundo do trabalho, terem emprego, aquando a conclusão do curso. 
No estudo de Monteiro (2015) em que também foi utilizada a ESTET, este aponta que as mulheres apresentam valores significativamente mais elevados na dimensão incerteza, o que é natural devido à dificuldade que sentem em encontrar um emprego quando comparadas com os homens. Esta dificuldade é explicada, maioritariamente, pelo envolvimento da mulher nas tarefas relacionadas com a maternidade e tarefas domésticas, implicando um afastamento das atividades profissionais; e ainda, o mundo do trabalho estar mais aberto à integração do masculino do que ao feminino (Fernandes, 2014; Monteiro, 2015).

Oliveira (2011) também defende que atualmente existem muitas desigualdades de género no mercado de trabalho, especialmente no que respeita à progressão de carreira das mulheres. No mesmo sentido, Nogueira (2006) constata que a maioria dos cargos de chefia de empresas e os salários mais elevados são atribuídos aos homens. $\mathrm{O}$ facto de os homens terem mais facilidade na entrada no mercado de trabalho, faz que as mulheres invistam mais na formação e tenham mais sucesso na mesma do que os primeiros, na expetativa de a formação ser um instrumento facilitador para contrariar as lógicas da dominância do masculino no mundo do trabalho (Fernandes, 2014; Monteiro, 2015; Ramos \& Gonçalves, 2014). Por isso, as mulheres planeiam e preparam mais atempadamente o seu futuro investindo na formação, ao contrário dos homens que, geralmente, tendem a fazer planos mais tardiamente, sendo mais desinvestido na formação (Fernandes, 2014; Monteiro, 2015).

Associada a esta constatação, sublinhe-se o facto de os homens percecionarem a frequência do ensino superior como uma obrigação imposta familiar e socialmente (Henderson-King \& Smith, 2006; Montei- ro, 2015); por isso a explicação do seu menor investimento quando comparados com as mulheres. E ainda, o aumento exponencial do desemprego estrutural desmobiliza os homens no investimento na formação, em virtude de percecionarem que o seu esforço presente não justifica as expetativas de um futuro próximo com sucesso profissional (Blustein, Kenna, Gill, \& DeVoy, 2008; Monteiro, 2015; Young et al., 2011).

Relativamente ao facto de as mulheres terem resultados superiores aos homens quanto à realização pessoal e à responsabilidade profissional, poderão ser explicados pelo investimento e preparação que as mulheres fizeram nas suas carreiras, percecionando a entrada no mundo do trabalho como uma oportunidade de realização pessoal e de assumir responsabilidades pessoais e sociais para encontrarem o seu espaço num contexto onde ainda predomina o masculino, e tenham conquistado o seu lugar numa situação de desvantagem (Fernandes, 2014; Monteiro, 2015; Oliveira, 2011). Este resultado pode, possivelmente, justificar-se pelo facto de as condições de trabalho, na maioria das entidades, ainda serem distintas para homens e mulheres, sendo que as mulheres são, maioritariamente, prejudicadas.

No que diz respeito à satisfação com a formação superior, não se registaram diferenças significativas entre os géneros. Talvez se possa justificar pela cultura específica da faculdade onde foram recolhidos os dados, sendo um contexto de grande heterogeneidade e tolerância pela diferença, em que ambos os géneros participam ativamente tanto em eventos como nos organismos estudantis. Contudo, no estudo de Benjamin e Hollings (1997), é destacado que os estudantes do sexo masculino se sentem mais satisfeitos com a vida em geral, onde está incluída a ver- 
tente académica, mas na dimensão sócio relacional o sexo feminino destaca-se como sendo o mais satisfeito. Contrariamente ao que defendem Aldemir e Gülcan (2004), que demonstram que as mulheres se sentem mais satisfeitas na sua experiência geral de vida académica.

Relativamente à variável ciclo de estudos, verificou-se diferenças na variável recursos pessoais, relativa à satisfação, na medida em que os estudantes de licenciatura apresentam valores inferiores aos de mestrado. Os primeiros tendem a ser mais novos, e portanto talvez ainda não tenham a perceção e maturidade necessárias para refletir acerca das suas competências, e de que forma as poderão utilizar no sentido de as potenciar e desenvolver. Noelke, Gebel e Kogan (2012) argumentam que é esperado que no mestrado, seja exigido que os alunos apresentem mais competências do que na licenciatura, e que a sua conclusão obriga a um maior esforço.

Aliado a isto, a experiência universitária dos estudantes vai-se desenvolvendo e melhorando à medida que os anos passam, devido ao facto de conhecerem cada vez melhor os professores, e o sistema de funcionamento da própria universidade, o que faz com que estes indivíduos se sintam mais satisfeitos, bem sucedidos, e auto confiantes, o que também poderá explicar os resultados obtidos nesta dimensão (Grayson, 2004; Rautopuro \& Vaisanen, 2001). Na mesma linha, Bebetsos e Goulimaris (2014) afirmam que à medida que o estudante vai ficando mais velho, tanto cronologicamente, como academicamente, mais estável e determinado será.

No que diz respeito aos alunos com funções associativistas, verificaram-se diferenças significativas na ESTEST. Os alunos sem experiência de associativismo sentem-se mais inseguros e ansiosos rela- tivamente à transição para o mercado de trabalho, talvez devido ao facto de os organismos estudantis serem uma oportunidade para os sujeitos treinarem aquilo que vai acontecer quando trabalharem no mundo real, o que faz com que os alunos pertencentes a estes grupos não se sintam tão preocupados.

Segundo Teixeira e Gomes (2004), quando os jovens pensam e chegam à conclusão que obter um emprego não será fácil, tentam participar em mais atividades extracurriculares, chegando mesmo a ter experiências no mercado de trabalho no último ano de curso, para que se sintam mais seguros e positivos relativamente à facilidade com que irão obter de emprego. Bayırbağ (2013) afirma que a participação dos estudantes em atividades extracurriculares (associativismo) pode determinar o rumo que a carreira do indivíduo vai tomar. Ainda, verificaram-se diferenças na dimensão sócio relacional da ESFS, o que poderá demonstrar que os alunos pertencentes a organismos estudantis possuem mais oportunidades de estabelecerem relações com os seus pares, com os professores, e membros da comunidade académica, quando comparados com os estudantes sem experiências de atividades associativas. É precisamente esta premissa que Pennington, Zvonkovic e Wilson (1989) defendem ao afirmar que os alunos mais envolvidos no ambiente universitário, onde poderá estar incluído o associativismo, se sentem mais satisfeitos do que os outros.

\section{Conclusão}

$\mathrm{Na}$ sua generalidade, os resultados deste estudo parecem indicar que a transição do ensino superior para o mercado de trabalho é algo que preocupa bastante os estudantes universitários da contemporaneidade, talvez devido à atual crise 
económica mundial com impactos incontornáveis na economia portuguesa, gerando desemprego estrutural, trabalho precário e temporário (Monteiro, 2015). Isto faz com que a incerteza seja um sentimento normal, pois ao mesmo tempo que o indivíduo se sente obrigado a tomar decisões definitivas que influenciem o seu futuro, depara-se com o desconhecido e com uma realidade bem distinta daquilo que tinha planeado (Abbott, 2005). Nos dias de hoje, é comum que os jovens permaneçam desempregados no período após o término do curso, e os que encontram emprego estão sujeitos a condições precárias, o que faz com que adiem a saída de casa dos pais e consequente emancipação (Nilsen, Guerreiro, \& Brannen, 2012; van der Velden \& Wolbers, 2003).

Se até há uns anos, em Portugal, um indivíduo se encontrava desempregado apenas devido ao desinteresse em obter um trabalho satisfatório ou de não se adaptar ao emprego, atualmente a taxa de desemprego é cada vez mais influenciada por fatores externos ao sujeito e passou a ser a regra, e não a exceção, mesmo entre pessoas com habilitações a nível de licenciatura ou mestrado (Arruda, 2010; Tedesco, 1998). Isto faz com que existam cada vez mais jovens a emigrar, em busca de independência e da realização dos seus sonhos e objetivos (Monteiro, 2015). Atualmente, a universidade já não é vista apenas como o local onde os estudantes adquirem e desenvolvem competências técnicas para o trabalho, mas é um tempo e lugar onde ocorre prioritariamente o desenvolvimento pessoal e social, que prepare o cidadão para a participação cívica e transformação social e pessoal (Monteiro, 2015).

Pavlidis (2012) argumenta que o trabalho dos educadores deve ser desenvolver o intelecto em geral, e fazer o indivíduo pensar criticamente acerca dos mais vari- ados tópicos: desde os seus sentimentos, capacidades, até uma visão filosófica do mundo. Esta constatação desafia as instituições do ensino superior a repensarem as suas práticas de ensino e aprendizagem, fundamentalmente centradas na transmissão da informação, que proporcionem aos estudantes oportunidades de fazerem aprendizagens sustentadas e com sentido crítico para os prepararem para os desafios das sociedades turbulentas onde possam encontrar o seu espaço de participação cívica (Monteiro \& Gonçalves, 2011). Deste modo, deve-se encorajar os estudantes a envolverem-se em mais atividades universitárias, tais como a frequência de seminários, por exemplo, assim como utilizar técnicas de aprendizagem ativa, relacionando as novas aprendizagens com experiências passadas e/ou o seu quotidiano (Chickering \& Gamson, 1987).

Segundo Clark (2001), as políticas educativas influenciam a forma como as universidades organizam a sua oferta formativa. Contudo, não é fácil transformar as práticas correntes enraizadas cultural e historicamente ao longo do tempo.

O autor propõe a criação de agências externas de avaliação que façam periodicamente o controle de qualidade da formação e investigação nas universidades, com avaliações capazes de produzir mudanças nos currículos, nas práticas pedagógicas, na qualidade da investigação produzida nos vários centros de investigação e na adequação da formação à realidade do mundo do trabalho, preparando os estudantes, de forma consistente, para os desafios do mundo do trabalho. Esta avaliação externa deveria generalizar-se a todas universidades públicas e privadas de cada país. Sublinhe-se que esta prática foi instituída em Portugal por Decreto-Lei $\mathrm{n}^{\circ}$ 369/2007, de 5 de novembro, promovida pelo Ministério do Ensino Superior em 
articulação com o Conselho de Reitores, através da Agência de Avaliação e Acreditação das formações do Ensino Superior dos vários ciclos de estudo (licenciatura, mestrados e doutoramentos).

Este estudo ressalta que as perceções antecipadas da transição da formação para o mundo do trabalho são experienciadas por parte dos estudantes como um acontecimento stressante. Esta constatação deveria mobilizar as instituições do ensino superior, especificamente os serviços de psicologia, para prepararem esta transição de vida com atividades ajustadas que minimizarem os efeitos stressantes desta transição. Como? Incentivando os estudantes a participarem, por exemplo, em atividades, workshops intencionalmente preparadas para este objetivo; a realizarem formação complementar e pósgraduada na sua área; promover e realizar cursos de línguas, requisito essencial a quase todas as áreas atualmente; proporcionar intervenções individuais e/ou em grupo para lidar com estas transições; promover o contacto de exploração direta com o tecido empresarial, através de miniestágios, contactos com profissionais, através de entrevistas antecipadamente preparadas e posteriormente integradas e refletidas (Monteiro, 2015); apoiar os estudantes e os já diplomados a elaborarem o curriculum vitae, adaptando-o à função a que se estão a candidatar, cartas de apresentação, e ainda fazendo a simulação de entrevistas de emprego, de forma a prepararem os sujeitos para processos de recrutamento.

Estas atividades intencionalmente preparadas, realizadas e integradas irão promover o desenvolvimento pessoal, o raciocínio e o pensamento crítico, o autoconhecimento e a componente social do sujeito, aspetos que deveriam ser cada vez mais priorizadas pela formação superior para garantirem o empoderamento dos seus formandos preparando-os para os desafios da contemporaneidade (Monteiro, 2015).

Também ressaltamos a importância de as instituições continuarem a apoiar os exalunos mesmo após a conclusão do curso. Isto porque a dificuldade em obter emprego na área pode ser um forte gerador de stress, especialmente sem o apoio próximo da instituição, que poderá fazer com que o indivíduo se sinta desamparado (Greco \& Roger, 2003; Sennett, 2007). Bayırbağ (2013) postula que o sucesso profissional dos estudantes depende dos investimentos e apoios que a universidade lhes proporciona ao longo da sua.

Os processos de socialização, as estratégias de procura de emprego, as ofertas disponíveis, e a filosofia de vida desenvolvida ao longo do curso, a articulação da universidade com o tecido laboral são também fatores decisivos que influenciam o processo de procura de emprego (Bayırbağ, 2013) e devem ser dinamizados intencionalmente pela própria instituição de ensino. A universidade deve ir de encontro às novas conceções de trabalho, pois atualmente, esta é bastante diferente daquilo que era há 50 anos. Os empregadores procuram pessoas ativas, dinâmicas, cooperantes, ter uma elevada capacidade analítica, e de resiliência (Fernandes \& Gonçalves, 2012).

Contudo, pelo facto de atualmente o mercado de trabalho se encontrar saturado e haver grande competitividade entre os trabalhadores, apesar de estes dedicarem cada vez mais horas do seu dia à atividade profissional, não existe a cultura da cooperação, da solidariedade e da interajuda entre os trabalhadores (Fernandes \& Gonçalves, 2012). 
As principais limitações do estudo prendem-se com o facto de a amostra ser de conveniência e se circunscrever, intencionalmente, à área geográfica do Grande Porto, à área da economia e da gestão. No futuro seria importante replicar este estudo em diferentes áreas de formação, com uma amostra aleatória, no sentido de compreender se os resultados se orientariam ou não no mesmo sentido. Seria pertinente ter em conta outras variáveis como a idade, tipo de instituições de ensino superior (públicas/privadas), experiência profissional prévia, etecetera.

Outra das limitações é ter assumido uma metodologia quantitativa. Articular uma metodologia quantitativa com uma qualitativa, através de entrevistas semiestruradas, ou grupos de discussão focalizada, entre outras, seria uma mais valia para a compreensão do problema porque, através da análise dos discursos dos participantes, teríamos acesso aos significados estruturantes da vivência da formação superior e da transição desta para o trabalho.

Outra das limitações é ser um estudo transversal e não longitudinal. Seria importante no futuro desenvolver investigações longitudinais para acompanhar os estudantes no processo da passagem da formação para a sua inserção na vida ativa e nos primeiros anos da sua atividade profissional.
Por fim, a principal limitação foi a confrontação da limitação da revisão do estado da arte sobre este domínio de investigação, dificultando a discussão dos resultados encontrados e a sustentabilidade concetual deste trabalho.

Uma vez que a investigação nesta área ainda é escassa, e porque é uma problemática que se encontra na agenda social e política das sociedades ocidentais, devido à crise económica que vem produzindo desemprego estrutural -não há trabalho na sociedade do trabalho (Arendt, 2001)-, sublinha-se a relevância deste estudo como um modesto contributo para compreender a forma como os estudantes finalistas da área de economia e gestão refletem e preparam a sua transição para o mercado de trabalho.

Este trabalho pretende ainda consciencializar as instituições do ensino superior de que a sua função não é apenas a transmissão de conhecimentos e que a sua missão não termina no momento em que os estudantes concluem o curso, mas devem assumir o compromisso de continuar a apoiá-los na transição para o trabalho a curto, médio e longo prazo para garantir que a sua entrada e permanência no mercado de trabalho seja o mais bemsucedida possível.

\section{Referências}

Abbott, J. (2005). Understanding and managing the unknown: The nature of uncertainty in planning. Journal of Planning Education and Research, 24(3), 237-251. http://dx.doi.org/10.1177/0739456X04267710

Aldemir, C. \& Gülcan, Y. (2004). Student satisfaction in higher education: A Turkish case. Higher Education Management and Policy, 16(2), 109-122. http://dx.doi.org/10.1787/hemp-v16-art19-en 
Almeida, L. S. \& Vasconcelos, R. (2008). Ensino superior em Portugal: Décadas de profundas exigências e transformações. Innovación Educativa, 18, 23-34. Retrieved from http://repositorium.sdum.uminho.pt/bitstream/1822/26572/1/6.3.15.pdf

Alves, M. G. (1998). Inserção na vida activa de licenciados: A construção de identidades sociais e profissionais. Sociologia - Problemas e Práticas, 26, 131-147. Retrieved from https://repositorio.iscte-iul.pt/bitstream/10071/787/1/7.pdf

Alves, M. G., Alves, N., \& Chaves, M. (2012). Inserção profissional e razoes de ingresso e reingresso no ensino superior: Um ponto de partida para uma temática em aberto. Sociologia-Problemas e Práticas, 69, 99-118. Retrieved from http://spp.revues.org/871

Arendt, H. (2001). A condição humana. Lisboa, Portugal: Relógio D’Água.

Arruda, M. C. C. (2010, May). A relação trabalho educação no cenário contemporâneo. Presented work in VII Seminário do Trabalho: Trabalho, Educação e Sociabilidade, Marília, Brasil.

Aspinwall, L. G. \& Taylor, S. E. (1992). Modeling cognitive adaptation: A longitudinal investigation of the impact of individual differences and coping on college adjustment and performance. Journal of Personality and Social Psychology, 63(6), 989-1003. http://dx.doi.org/10.1037/0022-3514.63.6.989

Bayırbağ, M. K. (2013). Is there a job after college?: Higher education's impact on transition from school to work. METU Studies in Development, 40(3), 465-492. Retrieved from https://is.gd/Kavi3Q

Bebetsos, E. \& Goulimaris, D. (2014). Personal outcome and leadership as defining factors of satisfaction in the context of the course "Arts II: Overview of Greek music and dance" of the Hellenic Open University. Turkish Online Journal of Distance Education, 15(2), 12-24. Retrieved from http://dergipark.ulakbim.gov.tr/tojde/article/view/5000102106/5000095205

Benjamin, M. \& Hollings, A. (1997). Student satisfaction: Test of an ecological model. Journal of College Student Development, 38(3), 213-228. Retrieved from http://eric.ed.gov/?id=EJ555102

Blustein, D. L., Kenna, A. C., Gill, N., \& DeVoy, J. E. (2008). The psychology of working: A new framework for counseling practice and public policy. The Career Development Quarterly, 56(4), 294-308. http://dx.doi.org/10.1002/j.2161-0045.2008.tb00095.x

Butt, B. Z. \& Rehman, K. U. (2010). A study examining the students satisfaction in higher education. Procedia - Social and Behavioral Sciences, 2(2), 5446-5450. http://dx.doi.org/10.1016/j.sbspro.2010.03.888

Campos, B. P. (1993). Consulta psicológica nas transições desenvolvimentais. Cadernos de Consulta Psicológica, 9, 5-9. Retrieved from https://repositorio-aberto.up.pt/bitstream/10216/5254/2/80991.pdf 
Chickering, A. W. \& Gamson, Z. F. (1987). Seven principles for good practice in undergraduate education. AAHE Bulletin, 17(3), 3-7. Retrieved from http://files.eric.ed.gov/fulltext/ED282491.pdf

Chickering, A. W. \& Schlossberg, N. K. (1995). How to get the most out of college. Needham Heights, Massachusetts: Allyn and Bacon.

Clark, B. (2001). The entrepreneurial university: New foundations for collegiality, autonomy, and achievement. Higher Education Management, 13(2), 9-24. Retrieved from http://eric.ed.gov/?id=EJ632944

Costa, A. F. \& Lopes, J. T. (Coords.) (2008). Os estudantes e os seus trajectos no ensino superior: Sucesso e insucesso, factores e processos, promoção de boas práticas. (Final report of FCT PSE/DIV/0001/2006, a project of the Programa de Promoção do Sucesso Escolar e Combate ao Abandono e ao Insucesso no Ensino Superior). Lisboa, Portugal. Retrieved from http://etes.cies.iscte.pt/Ficheiros/relatorio_ETES_completo.pdf

Delors, J., Al-Mufti, I., Amagi, I., Carneiro, R., Chung, F., Geremek, B., ... Nanzhao, Z. (2010). Educação, um tesouro a descobrir: Relatório para a UNESCO da Comissão Internacional sobre Educação para o Século XXI. São Paulo, Brasil: Cortez / Unesco. Retrieved from http://unesdoc.unesco.org/images/0010/001095/109590por.pdf

Fernandes, F. S. (2014). Estilo parental e desenvolvimento vocacional: Um estudo sobre a influência das famílias na orientação dos adolescentes. São Paulo, Brasil: Edições Loyola.

Fernandes, F. S. \& Gonçalves, C. (2012). Transformações no mundo do trabalho e seus significados: Como orientar em tempos de crise? Presented work in XIII Congreso Internacional de Galicia e Norte de Portugal de Formación Para o Traballo. Retrieved from https://repositorio-aberto.up.pt/bitstream/10216/63491/2/89980.pdf

Gonçalves, C. M. (2014). Evoluções recentes do desemprego em Portugal. Sociologia, 15(1), 125-164. Retrieved from https://repositorio-aberto.up.pt/bitstream/10216/7767/2/3723.pdf

Grayson, J. P. (2004). The relationship between grades and academic program satisfaction over four years of study. Canadian Journal of Higher Education, 34(2), 1-34. Retrieved from

http://journals.sfu.ca/cjhe/index.php/cjhe/article/viewFile/183455/183408

Greco, V. \& Roger, D. (2003). Uncertainty, stress, and health. Personality and Individual Differences, 34(6), 1057-1068.

http://dx.doi.org/10.1016/S0191-8869(02)00091-0

Henderson-King, D. \& Smith, M. N. (2006). Meanings of education for university students: Academic motivation and personal values predictors. Social Psychology of Education, 9(2), 195-221.

http://dx.doi.org/10.1007/s11218-006-0006-4 
Hoerger, M. \& Currell, C. (2012). Ethical issues in internet research. In S. J. Knapp, M. C. Gottlieb, M. M. Handelsman, \& L D. VandeCreek (Eds.), APA handbook of ethics in psychology, Vol. 2: Practice, teaching, and research (pp. 385-400). Washington, District of Columbia: American Psychological Association. http://dx.doi.org/10.1037/13272-018

Kehm, B. M. \& Stensaker, B. (Eds.) (2009). University rankings, diversity, and the new landscape of higher education. Rotherdam, The Netherlands: Sense Publishers.

Leuze, K. (2011). How structure signals status: Institutional stratification and the transition from higher education to work in Germany and Britain. Journal of Education and Work, 24(5), 449-475.

http://dx.doi.org/10.1080/13639080.2011.596524

Lima, P. \& Coimbra, J. L. (2004). Narrativas de investimento vocacional contributo para a revisão das práticas de orientação vocacional no contexto escolar. Presented work in V Congreso Internacional de Galicia e Norte de Portugal de Formación Para o Traballo. Retrieved from https://repositorio-aberto.up.pt/bitstream/10216/62427/2/84841.pdf

Magalhães, B. \& Silva, G. (2010, May). Capitalismo, trabalho, género e educação. Paper presented at the VII Seminário do Trabalho: Trabalho, Educação e Sociabilidade. Retrieved from https://is.gd/2d8dGi

Marconi, M. A. \& Lakatos, E. M. (1985). Fundamentos de metodologia científica. São Paulo, Brasil: Editora Atlas.

Marginson, S. \& van der Wende, M. (2007). Globalisation and higher education. OECD Education Working Papers, 8, 1-85. http://dx.doi.org/10.1787/173831738240

de Melo, S. L. \& Borges, L. (2007). A transição da universidade ao mercado de trabalho na ótica do jovem. Psicologia Ciência e Profissão, 27(3). 376-395. Retrieved from http://www.scielo.br/pdf/pcp/v27n3/v27n3a02

Monteiro, A. (2015). (Re)ssignificando a educação superior: Da educação à transição para o trabalho. Unpublished doctoral dissertation, Universidade do Porto, Porto, Portugal.

Monteiro, A. M. \& Gonçalves, C. M. (2011). Desenvolvimento vocacional no ensino superior: Satisfação com a formação e desempenho académico. Revista Brasileira de Orientação Profissional, 12(1), 15-27. Retrieved from

https://is.gd/ZsbSCi

Monteiro, A. M., Santos, P. J., \& Gonçalves, C. M. (2015). Building a scale of the meanings of transition from higher education to work. Journal of Career Assessment, 23(3), 481-492. http://dx.doi/org/10.1177/1069072714547614

Nilsen, A., Guerreiro, M. D. D., \& Brannen, J. (2002). Most choices involve money: Different pathways to adulthood. In J. Brannen, S. Lewis, A. Nilsen \& J. Smithson (Eds.), Young Europeans, work and family: Futures in transition. (pp. 162-184). London, England: Routledge. 
Noelke, C., Gebel, M., \& Kogan, I. (2012). Uniform inequalities: Institutional differentiation and the transition from higher education to work in post-socialist Central and Eastern Europe. European Sociological Review, 28(6), 704-716.

http://dx.doi.org/10.1093/esr/jcs008

Nogueira, M. C. O. C. (2006). Os discursos das mulheres em posições de poder. Cadernos de Psicologia Social do Trabalho, 9(2), 57-72.

http://dx.doi.org/10.11606/issn.1981-0490.v9i2p57-72

Oliveira, N. (2011). Mulheres nas engenharias: Dificuldades no mercado de trabalho. Unpublished master's thesis, Universidade do Minho, Portugal. Retrieved from https://is.gd/mS0yI0

Pascarella, E. T. \& Terenzini, P. T. (2005). How college affects students: A third decade of research, Vol. 2. San Francisco, California: Jossey-Bass Publishers.

Pavlidis, P. (2012). The rise of general intellect and the meaning of education: Reflections on the contradictions of cognitive capitalism. Journal for Critical Education Policy Studies, 10(1), 37-52. Retrieved from

http://www.jceps.com/wp-content/uploads/PDFs/10-1-03.pdf

Pennington, D. C., Zvonkovic, A. M., \& Wilson, S. L. (1989). Changes in college satisfaction across an academic term. Journal of College Student Development, 30(6), 528-535. Retrieved from http://eric.ed.gov/?id=EJ406591

Pinheiro, A. C. D. \& da Silva, B. D. (2004). A estruturação do processo de recolha de dados on-line. Presented work in X Conferência Internacional Avaliação Psicológica, Formas e Contextos. Braga, Portugal.

Ramos, A. (2008). A satisfação dos estudantes com a formação superior. Unpublished master's thesis. Universidade do Porto, Porto, Portugal.

Ramos, A. \& Gonçalves, C. M. (2014). Escala de Satisfação com a Formação Superior (ESFS). In L. S. Almeida, M. R. Simões, \& M. M. Gonçalves (Eds.), Instrumentos e contextos de avaliação psicológica, Vol. 2. (pp. 153-168). Coimbra, Portugal: Almedina.

Rautopuro, J. \& Vaisanen, P. (2001, September). Non-traditional students at university: A follow-up study of young and adult students' orientations, satisfaction and learning outcomes. Paper presented at the European Conference on Educational Research, Lille, France. Retrieved from

http://www.leeds.ac.uk/educol/documents/00001880.htm

Santos, L. F. O. (2009). Tornar-se homem: Dramaturgias em torno das apresentações de si, das emoções e dos afectos em palcos offline e online. Unpublished doctoral dissertation, Universidade do Minho, Portugal. Retrieved from http://repositorium.sdum.uminho.pt/bitstream/1822/10157/1/tese.pdf

Schlossberg, N. K. (1981). A model for analyzing human adaptation to transition. The Counseling Psychologist, 9(2), 2-18. http://dx.doi.org/10.1177/001100008100900202 
Schlossberg, N. K. (2011). The challenge of change: The transition model and its applications. Journal of Employment Counselling, 48(4), 159-162.

http://dx.doi.org/10.1002/j.2161-1920.2011.tb01102.x

Sennett, R. (2007). A cultura do novo capitalismo. Lisboa, Portugal: Relógio D‘Água.

Tedesco, J. C. (1998). O novo pacto educativo: Educação, competitividade e cidadania na sociedade moderna. São Paulo, Brasil: Ática.

Teixeira, M. A. P. \& Gomes, W. B. (2004). Estou-me formando... E agora? Reflexões e perspectivas de jovens formandos universitários. Revista Brasileira de Orientação Profissional, 5(1), 47-62. Retrieved from

http://pepsic.bvsalud.org/pdf/rbop/v5n1/v5n1a05.pdf

Urbano, C. (2011). A (id)entidade do ensino superior politécnico em Portugal: Da lei de bases do sistema educativo à declaração de Bolonha. Sociologia, Problemas e Práticas, $66,95-115$. Retrieved from

https://is.gd/fiwyyg

van der Velden, R. K. W. \& Wolbers, M. H. J. (2003). The integration of young people into the labour market: The role of training systems and labour market regulation. In W. Müller \& M. Gangl (Eds.), Transition from education to work in Europe: The Integration of Youth into EU Labour Markets (pp. 186-211). New York, New York: Oxford University Press.

http://dx.doi.org/10.1093/0199252475.003.0007

Walter, S. A., Tontini, G., \& Domingues, M. J. C. S. (2005). Identificando oportunidades de melhoria em um curso superior através da análise da satisfação dos alunos. Presented work in Encontro nacional dos programas de pós-graduação em administração: Brasília, Brasil. Retrieved from https://is.gd/naBngC

Young, R. A., Marshall, S. K., Valach, L., Domene, J. F., Graham, M. D., \& Zaidman-Zait, A. (2011). Transition to adulthood: Action, projects, and counseling. New York, New York: Springer.

http://dx.doi.org/10.1007/978-1-4419-6238-6

Data de recebimento: 7 de março de 2016

Data de aceitação: 1 de junho de 2016 